\title{
DEVELOPMENT OF EDUCATIONAL MATERIAL FOR NUTRITION AND HYPERTENSION
}

\author{
Didit Damayanti ${ }^{1}$, Antonius Sri Hartono ${ }^{1}$, Nils Aria Zulfianto ${ }^{1}$, Mimin Aminah ${ }^{2}$ \\ ${ }^{1}$ Jurusan Gizi, Politeknik Kesehatan Kemenkes Jakarta II, Jakarta 12120 \\ 2Jurusan Gizi, Politeknik Kesehatan Kemenkes Bandung, Bandung, Jawa Barat 40171 \\ Email : diditdamayanti@yahoo.com
}

\begin{abstract}
High prevalence of hypertension in Indonesia (25.8\%) should be prevented because it affects the onset of disease complications, reduced productivity and increased health care costs. Until now, there has not found the media developed specifically to prevent and treat hypertension. The study aims was developed and assessed the use of nutrition and hypertension media for counseling. The research started with the development of educational media. The study design was post test using nutrition and hypertension media by intervention group compared to the control group using hypertension leaflet. Age, duration of working respondents did not differ significantly ( $p>0.05)$ among 17 respondents from intervention group and 14 respondents from control group. The study showed the score usage of media was 3.16 higher among intervention group than the control group 2.99. However, Mann-Whitney test showed no significant differences ( $p>0.05$ ). From fourteen aspects result showed significant scores differences $(\mathrm{p}<0.05)$ on the aspects of appearance of image and colors. The used of key pieces of media seemed helpful $(52.94 \%-76.47 \%)$ and very helpful $(23.53 \%-47.06 \%)$ for majority of respondents during counseling. It suggested that educational media of nutrition and hypertension can be reproduce and use in the primary health care.
\end{abstract}

Keywords: nutrition, hypertension, media education

\section{PENGEMBANGAN MEDIA EDUKASI LEMBAR BALIK GIZI DAN HIPERTENSI}

\begin{abstract}
ABSTRAK
Prevalensi hipertensi yang tinggi di Indonesia $(25,8 \%)$ harus dicegah karena dapat mempengaruhi timbulnya komplikasi penyakit, mengurangi produktivitas kerja dan meningkatkan biaya perawatan kesehatan. Sampai saat ini, belum ditemukan media yang dikembangkan secara khusus untuk mencegah dan mengobati hipertensi. Tujuan penelitian ini adalah mengembangkan dan menilai penggunaan media gizi dan hipertensi untuk konseling. Penelitian dimulai dengan pengembangan media lembar balik gizi dan hipertensi. Rancangan penelitian adalah post test dengan menggunakan lembar balik gizi dan hipertensi pada kelompok intervensi dibandingkan kelompok kontrol yang menggunakan leaflet hipertensi. Karakteristik usia, lama masa kerja responden tidak berbeda secara signifikan $(p>0,05)$ di antara 17 responden dari kelompok intervensi dan 14 responden dari kelompok kontrol. Hasil penelitian menunjukkan bahwa skor penggunaan media adalah 3,16 lebih tinggi pada kelompok intervensi dibandingkan kelompok kontrol yaitu 2,99. Namun, uji Mann-Whitney tidak menunjukkan perbedaan yang signifikan ( $>>0,05)$. Dari empat belas aspek penilaian lembar balik gizi dan hipertensi hasil penelitian menunjukkan perbedaan skor yang signifikan $(\mathrm{p}<0,05)$ pada aspek tampilan gambar dan warna. Penggunaan kunci media lembar balik gizi dan hipertensi nampaknya membantu $(52,94 \%$ - 76,47\%) dan sangat membantu $(23,53 \%-47,06 \%)$ mayoritas responden dalam melaksanakan konseling. Disarankan agar media lembar balik gizi dan hipertensi dapat diproduksi ulang dan digunakan dalam pelayanan kesehatan primer di Puskesmas dan Posbindu.
\end{abstract}

Kata kunci:: gizi, hipertensi, media edukasi 


\section{PENDAHULUAN}

Data penyakit tidak menular (PTM) menunjukkan prevalensi yang meningkat di Indonesia(1). Salah satu penyakit tidak menular yang tinggi prevalensinya adalah hipertensi. Tingginya prevalensi hipertensi di Indonesia (25,8\%) (2) perlu dicegah karena berdampak pada timbulnya komplikasi penyakit yang lebih parah, berkurangnya produktifitas kerja karena sakit, dan meningkatnya pengeluaran biaya kesehatan (3) (4). World Health Organization (WHO) merekomendasikan gaya hidup sehat termasuk tidak merokok dan minum minuman beralkohol, mengkonsumsi makanan sehat termasuk sayur dan buah, melakukan aktifitas fisik secara teratur untuk memelihara berat badan normal serta mengelola stress mental(4). Demikian juga dengan diet DASH (Dietary Approach to prevent and treat hypertension) yang antara lain menganjurkan meningkatkan konsumsi sayur dan buah untuk mengatasi hipertensi (5)

Untuk membantu mengubah perilaku, lembar balik merupakan salah satu media cetak yang memiliki bentuk atau ukuran yang lebih besar, gambar dan tulisan yang lebih besar, sehingga memiliki keunggulan interaktif yang lebih baik untuk keperluan konseling dibanding dengan leaflet(6)(7). Puskesmas di Jakarta Selatan selama ini hanya menggunakan leaflet untuk melakukan edukasi kepada pasien hipertensi (8). Sejauh ini belum juga ditemui adanya media lembar balik yang dikembangkan khusus untuk mencegah dan mengatasi hipertensi. Berdasarkan latar belakang diatas, maka perlu dilakukan penelitian yang bertujuan mengembangkan serta menilai penggunaan media edukasi lembar balik gizi dan hipertensi untuk konseling.

\section{METODE PENELITIAN}

Penelitian pengembangan media lembar balik hipertensi ini terdiri dari beberapa tahap. Dimulai dengan pengkajian mengenai bentuk dan isi media edukasi hipertensi oleh petugas kesehatan di puskesmas, pakar, dan peserta Pos Pembinaan Terpadu (Posbindu). Peserta posbindu dilibatkan dengan alasan lembar balik gizi dan hipertensi ini akan digunakan di puskesmas dan posbindu (9). Dilanjutkan dengan uji coba penggunaan media lembar balik hipertensi oleh petugas kesehatan. Instrumen skor penilaian media dikembangkan menggunakan 4 skala likert (10). Rancangan penelitian adalah post test dengan kelompok control (10). Populasi

Tabel 1. Karakteristik sampel pada dua kelompok penelitian.

\begin{tabular}{llcc}
\hline Karakteristik & Kelompok & $\mathrm{n}$ & Rerata \pm SD \\
\hline Usia (tahun) & Media leaflet & 14 & $41.0 \pm 7.4$ \\
& Media lembar balik & 17 & $40.3 \pm 9.1$ \\
Lama bekerja (tahun) & Media leaflet & 14 & $13.9 \pm 8.8$ \\
& Media lembar balik & 17 & $15.7 \pm 10.0$ \\
Pengalaman memberikan konseling & Media leaflet & 14 & $12.6 \pm 9.5$ \\
(tahun) & Media lembar balik & 17 & $13.8 \pm 8.1$ \\
\hline $\mathrm{p}>0.05$ & & &
\end{tabular}



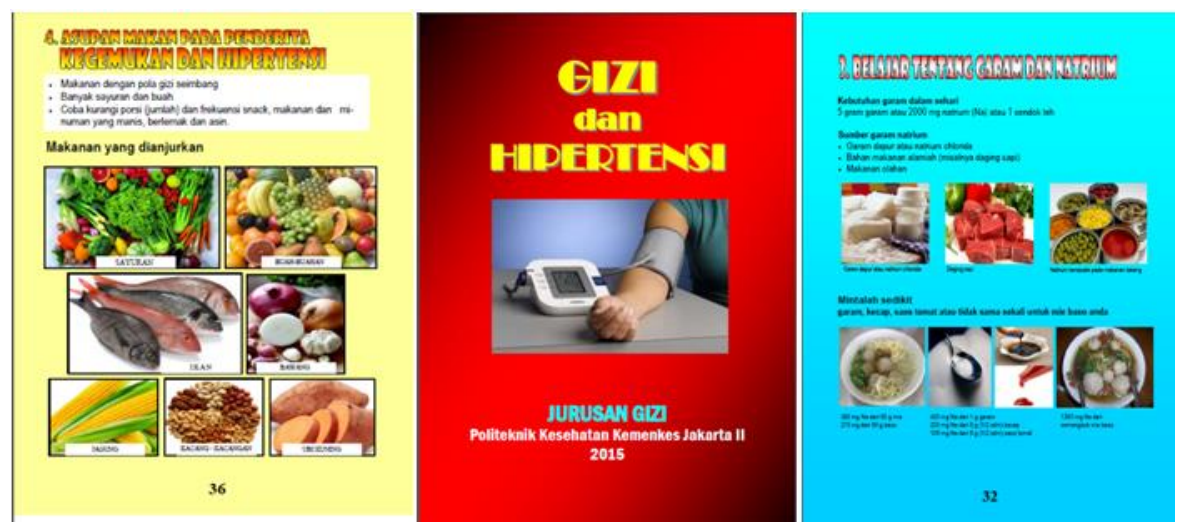

Gambar 1. Contoh isi lembar balik gizi dan hipertensi

adalah petugas kesehatan yang mengelola posbindu, poli PTM atau poli gizi yang bertempat tinggal di DKI Jakarta dan Bandung. Sedangkan sampel uji coba penggunaan media edukasi adalah semua petugas kesehatan yang bertanggung jawab responden yang menggunakan lembar balik dan 14 responden yang menggunakan media leaflet hipertensi (Tabel 1). Uji statistik menggunakan chi-square, t-tes dan mann-whitney tes.

Tabel 3. Uji perbedaan penilaian penggunaan lembar balik dan leaflet dalam konseling

\begin{tabular}{llcc}
\hline & Kelompok & $\mathrm{n}$ & Mean (CI 95\%) \\
\hline Rata-rata hasil penilaian & Media leaflet & 14 & $2.99(2.77,3.21)$ \\
& Media lembar balik & 17 & $3.16(3.01,3.31)$
\end{tabular}

Uji Mann-whitney dengan $\mathrm{p}=0.238$

pada kegiatan posbindu, pos lansia, poli PTM atau poli gizi sebanyak 31 orang, dengan perincian masing-masing 18 orang dari 20 puskesmas di Jakarta Selatan dan 13 orang dari 13 puskesmas di Cimahi, Bandung.

Kelompok intervensi menggunakan lembar balik gizi dan hipertensi sedangkan kelompok kontrol menggunakan leaflet hipertensi untuk konseling. Hasil uji t dan chi-square menunjukkan karakteristik usia, lama bekerja responden tidak berbeda secara bermakna $(\mathrm{p}>0.05)$ diantara 17

\section{HASIL DAN PEMBAHASAN}

Lembar balik gizi hipertensi dan kunci lembar balik berhasil dikembangkan sesuai dengan tahapan yang direncanakan. Materi lembar balik gizi dan hipertensi bersumber dari Pedoman Gizi Seimbang, Leaflet Diet Rendah Garam, buku saku Waspadailah Hipertensi serta pengembangannya (11) (12) (13). Draft lembar balik pertama dikembangkan berdasarkan pengkajian kebutuhan petugas kesehatan di puskesmas. Draft lembar balik kedua merupakan 
Tabel 4. Perbedaan penilaian media edukasi gizi hipertensi berdasarkan aspek penilaian

\begin{tabular}{|c|c|c|c|c|}
\hline Aspek Penilaian & Kelompok & $\mathrm{n}$ & Rerata $\pm \mathrm{SD}$ & p-value \\
\hline \multirow[t]{2}{*}{ Kelengkapan materi } & Media leaflet & 14 & $3.00 \pm 0.39$ & \multirow{2}{*}{0.289} \\
\hline & Media lembar balik & 17 & $3.18 \pm 0.52$ & \\
\hline \multirow[t]{2}{*}{ Kemudahan mengkaji } & Media leaflet & 14 & $2.93 \pm 0.47$ & \multirow{2}{*}{0.766} \\
\hline & Media lembar balik & 17 & $2.94 \pm 0.74$ & \\
\hline \multirow{2}{*}{$\begin{array}{l}\text { Kemudahan memecahkan } \\
\text { masalah kasus }\end{array}$} & Media leaflet & 14 & $3.00 \pm 0.55$ & \multirow{2}{*}{0.710} \\
\hline & Media lembar balik & 17 & $2.94 \pm 0.24$ & \\
\hline \multirow{2}{*}{$\begin{array}{l}\text { Kemudahan menyampaikan } \\
\text { pesan }\end{array}$} & Media leaflet & 14 & $3.00 \pm 0.55$ & \multirow{2}{*}{0.744} \\
\hline & Media lembar balik & 17 & $2.94 \pm 0.42$ & \\
\hline \multirow[t]{2}{*}{ Isi pesan mudah dipahami } & Media leaflet & 14 & $3.07 \pm 0.47$ & \multirow{2}{*}{0.525} \\
\hline & Media lembar balik & 17 & $3.18 \pm 0.39$ & \\
\hline \multirow[t]{2}{*}{ Interaksi dengan klien } & Media leaflet & 14 & $3.21 \pm 0.42$ & \multirow{2}{*}{0.619} \\
\hline & Media lembar balik & 17 & $3.29 \pm 0.47$ & \\
\hline \multirow[t]{2}{*}{ Penampilan gambar } & Media leaflet & 14 & $2.79 \pm 0.89$ & \multirow{2}{*}{$0.052 * *$} \\
\hline & Media lembar balik & 17 & $3.35 \pm 0.49$ & \\
\hline \multirow[t]{2}{*}{ Penampilan tata letak } & Media leaflet & 14 & $2.79 \pm 0.57$ & \multirow{2}{*}{0.091} \\
\hline & Media lembar balik & 17 & $3.12 \pm 0.48$ & \\
\hline \multirow[t]{2}{*}{ Penampilan warna } & Media leaflet & 14 & $2.64 \pm 1.00$ & \multirow{2}{*}{$0.032 *$} \\
\hline & Media lembar balik & 17 & $3.35 \pm 0.49$ & \\
\hline \multirow[t]{2}{*}{ Penampilan huruf } & Media leaflet & 14 & $3.00 \pm 0.39$ & \multirow{2}{*}{0.453} \\
\hline & Media lembar balik & 17 & $3.12 \pm 0.48$ & \\
\hline \multirow[t]{2}{*}{ Penampilan ukuran media } & Media leaflet & 14 & $3.07 \pm 0.47$ & \multirow{2}{*}{0.761} \\
\hline & Media lembar balik & 17 & $3.00 \pm 0.70$ & \\
\hline \multirow[t]{2}{*}{ Material media } & Media leaflet & 14 & $3.00 \pm 0.39$ & \multirow{2}{*}{0.133} \\
\hline & Media lembar balik & 17 & $3.24 \pm 0.43$ & \\
\hline \multirow[t]{2}{*}{ Tingkat kesukaan } & Media leaflet & 14 & $3.07 \pm 0.61$ & \multirow{2}{*}{0.849} \\
\hline & Media lembar balik & 17 & $3.12 \pm 0.33$ & \\
\hline \multirow[t]{2}{*}{ Manfaat media } & Media leaflet & 14 & $3.29 \pm 0.61$ & \multirow{2}{*}{0.268} \\
\hline & Media lembar balik & 17 & $3.53 \pm 0.51$ & \\
\hline
\end{tabular}

* bermakna pada $\mathrm{p}<0.0 .5$ dengan uji Mann-whitney; **bermakna pada $\mathrm{p}$ borderline dengan uji Mann-whitney

perbaikan draft lembar balik pertama yang telah mendapat masukan dari para ahli dan pemangku kebijakan dari Kementerian Kesehatan. Lembar balik terakhir diperbaiki setelah mendapat masukan dari peserta posbindu dan pos lansia di Jakarta dan Bandung. Lihat Gambar 1. Berdasarkan diskusi ditetapkan bahwa sasaran pengguna adalah petugas kesehatan bukan kader, walaupun dengan tambahan pelatihan kader mungkin juga dapat menggunakan lembar balik ini. Tahapan pengembangan media ini hampir sama dengan studi yang dilakukan oleh Ali (2009) yang meliputi analisis kebutuhan, perancangan dan pengembangan media, 
pengujian dan implementasi (14). Setelah mendapat masukan media edukasi lembar balik dikembangkan dengan membuat script isi lembar balik terlebih dahulu.

Lembar balik gizi dan hipertensi secara umum berisi informasi yang relatif lengkap dimulai dengan pengertian dan ukuran tekanan darah, gejala, penyebab, faktor resiko, akibat atau komplikasi yang diakibatkan hipertensi, cara pencegahan dan mengatasinya dari aspek olahraga, pemantauan $\mathrm{BB}$, pengaturan makan serta pengobatan. Secara khusus lembar balik ini dikembangkan sesuai kompetensi gizi yang dimiliki peneliti. Sehingga lembar balik berisi pesan tentang garam, natrium dan sumbernya, nasehat tentang asupan makanan untuk berbagai kondisi yaitu kondisi hipertensi dan kegemukan; hipertensi, DM dan kegemukan; hipertensi dan DM; hipertensi dan penyakit ginjal; hipertensi, kegemukan dan dislipidemia (Lihat Gambar 1). Sebagai tambahan lembar balik ini dilengkapi dengan kunci lembar balik yang secara umum berfungsi membantu pengguna untuk mencari pesan yang diinginkan dengan cepat.

Penilaian penggunaan lembar balik nampak cukup baik dibandingkan dengan penggunaan leaflet. Skor penilaian penggunaan lembar balik adalah 3.16 (CI $95 \%: 3.01,3.31)$ lebih tinggi dari pada kelompok yang menggunakan leaflet yaitu 2.99 (CI 95\%: 2.77, 3.21). Namun hasil uji Mann-whitney menunjukkan perbedaan skor penilaian yang tidak bermakna secara statistik ( $p>0.05)$. (Tabel 3). Analisa dari 14 aspek penilaian (Tabel 4) menunjukkan adanya perbedaan skor penilaian yang bermakna $(p<0.05), \quad$ pada aspek penampilan gambar dan warna. Penggunaan kunci lembar balik nampak membantu $(52.94 \%$ - 76.47\%) dan sangat membantu $(23.53 \%$ - $47.06 \%)$ sebagian besar responden dalam melakukan konseling.

Walaupun penilaian penggunaan lembar balik nampak lebih baik dari pada pada penggunaan leaflet dalam kegiatan konseling, namun hasil uji mann-whitney menunjukkan perbedaan nilai kedua media edukasi tersebut tidak berbeda secara bermakna ( $\mathrm{p}=0.238)$. Jika dibandingkan dengan penelitian Ali (2009) yang melakukan uji coba media pembelajaran, nampak penilaian pada penelitian ini lebih rendah (14). Perbedaan penilaian media pada dua penelitian ini mungkin disebabkan pada penelitian Ali (2009) tidak menggunakan kontrol.

Hal-hal yang mungkin menyebabkan hasil penelitian ini tidak bermakna adalah jumlah sampel yang sedikit. Walaupun nampaknya rata-rata nilai penggunaan lembar balik lebih baik daripada penggunaan leaflet. Dari 32 orang sampel yang direncanakan, terdapat 2 orang yang tidak bisa hadir pada saat penelitian dikarenakan kesibukan pekerjaan. Kemungkinan yang lain adalah tidak ditemukannya media edukasi yang setara dengan lembar balik, sehingga yang digunakan sebagai kontrol adalah media leaflet yang digunakan di salah satu puskesmas di Jakarta. Sedangkan media lembar balik yang ada adalah lembar balik penyakit DM, lembar balik lansia dan lembar balik PTM yang hanya berisi nasehat tentang penyakitnya.

Berdasarkan empat belas aspek penilaian, hasil uji Mann-whitney menunjukkan adanya perbedaan yang bermakna antara kedua media yaitu pada aspek penilaian gambar $(\mathrm{p}=0.052)$ dan warna media (0.032) (lihat tabel). Hasil penelitian ini sesuai dengan teori bahwa kelebihan lembar balik dibandingkan leaflet adalah kemampuan menampilkan gambar dan warna yang lebih menarik karena bentuknya yang lebih besar dari 
pada leaflet (6).

Peneliti tidak dapat membandingkan hasil penelitian ini dengan penelitian sejenis dikarenakan metode dan desain penelitian yang berbeda. Hasil-hasil penelitian sejenis menilai tingkat keefektifan pengembangan media dengan membandingkan hasil pre dan post tes pengetahuan klien setelah menerima materi dengan menggunakan media yang dikembangkan. Misalnya penggunaan permainan ular tangga yang dapat meningkatkan nilai post tes mata pelajaran IPA, IPS dan Bahasa (15). Demikian juga dengan penelitian sebelumnya yang menunjukkan adanya perbedaan pengetahuan kesehatan gigi yang bermakna antara kelompok yang diajar menggunakan media power point dibandingkan menggunakan flip chart (16).

\section{SIMPULAN DAN SARAN}

Lembar balik gizi dan hipertensi beserta kunci lembar balik nampaknya dapat digunakan oleh petugas kesehatan untuk melakukan konseling. Disarankan penelitian dilanjutkan dengan melihat dampak konseling terhadap perubahan pengetahuan klien serta memperbanyak lembar balik gizi dan hipertensi beserta kunci lembar balik untuk dapat digunakan dalam kegiatan konseling dan penyuluhan di puskesmas, baik di posbindu, poli PTM maupun di poli gizi.

\section{UCAPAN TERIMA KASIH}

Penelitian ini didanai oleh DIPA Badan PPSDM Kesehatan untuk Penelitian Unggulan Perguruan Tinggi Tahun 2015

\section{DAFTAR PUSTAKA}

1. Direktorat Jenderal Pengendalian Penyakit dan Penyehatan Lingkungan Kemenkes RI. Profil Pengendalian Penyakit dan Penyehatan Lingkungan Tahun 2012. 2013.

2. Badan Penelitian dan Pengembangan Kesehatan Kemenkes RI. RISET KESEHATAN DASAR. 2013.

3. US Department of Health and Human Services, National Institutes of Health, National Heart Lung and Blood. Prevention, Detection, Evaluation, and Treatment of High Blood Pressure. 2004.

4. Region SA. Noncommunicable Diseases in the South-East Asia Region. 2011.

5. Appel LJ, Brands MW, Daniels SR, Karanja N, Elmer PJ, Sacks FM. Dietary Approaches to Prevent and Treat Hypertension A Scientific Statement From the American Heart Association. 2006;296-309.

6. Moss G. Visual ways. 1985.

7. Akademi Gizi dan IKIP Malang. Hasil Lokakarya Audio Visual Aids. 1995.

8. Puskesmas Kecamatan Cilandak Jakarta Selatan. Leaflet Hipertensi: Kenali dan cegah hipertensi". 2015.

9. Departemen Kesehatan RI. Pos Pembinaan Terpadu Penyakit Tidak Menular. 2008.

10. Notoatmodjo S. Metode Penelitian Kesehatan. 2017.

11. Kementerian Kesehatan RI. Pedoman gizi seimbang. 2014.

12. Instalasi Gizi RSCM dan PERSAGI. Leaflet "Diet Rendah Garam." 1998.

13. Kementrian Kesehatan RI. Buku Saku "Waspadai Hipertensi: Kendalikan Tekanan Darah.” 2014.

14. Ali M. Pengembangan media Pembelajaran Interaktif Mata Kuliah Elektromagnetik. J Edukasi@Elektro. 2009;5(1):11-8. 
15. Nugrahani R. Media Pembelajaran Berbasis Visual Berbentuk Ular Tangga Untuk Meningkatkan Kualitas Belajar Mengajar Di Sekolah Dasar. Lembaran Ilmu Kependidikan. 2007;36(1):35-44.

16. Oki N, Eram TP, Bambang W. Perbandingan media power point dengan flip chart dalam meningkatkan pengetahuan kesehatan gigi dan mulut. Unnes J public Heal. 2012;1(1). 